\title{
O diagnostico da síndrome do carcinoma nevoide basocelular (Gorlim-Goltz)
}

Diagnosis of basocellular nevoid carcinoma syndrome (Gorlim-Goltz)

El diagnóstico de la síndrome del carcinoma nevoide basocelular (Gorlim-Goltz)

\author{
Maylson Alves Nogueira BARROS ${ }^{1}$ \\ Vitor Bruno TESLENCO ${ }^{1}$ \\ Guilherme Nucci dos REIS ${ }^{2}$ \\ Arnobio Luiz NUNES ${ }^{2}$ \\ Everton Floriano PANCINI ${ }^{3}$ \\ Herbert de Abreu CAVALCANTI
}

${ }^{I}$ Residente em Cirurgia e Traumatologia Bucomaxilofacial, Associação Beneficente da

${ }^{2}$ Preceptor do programa de residencia em Cirurgia e Traumatologia Bucomaxilofacial, Associação Beneficente da Santa Casa, 79002-251, Campo Grande - MS ${ }^{3}$ Preceptor e chefe do serviço de Cirurgíia e Traumatologia Bucomaxilofacial, Associação Beneficente da Santa Casa, 79002-251, Campo Grande - MS

${ }^{4}$ Preceptor e coordenador da residencia de Cirurgia e Traumatologia Bucomaxilofacial, Associação Beneficente da Santa Casa, 79002-251, Campo Grande - MS

\section{Resumo}

Introdução: A síndrome de Gorlin-Goltz é compreendida como uma condição hereditária autossômica dominante, causada por uma alteração no gene patched (PTCH), localizado no cromossomo 9q22.3-q31, este gene regula as funções de supressão tumoral, organização embrionária e ciclo celular, as mutações no gene PTCH levam a o efeito da perda de controle de vários outros genes responsaveis pela organogênese, carcinogênese e odontogênese. Objetivo: O presente trabalho tem como objetivo descrever um caso onde o paciente foi diagnosticado com a Síndrome do carcinoma nevoide basocelular. Relato de caso: Paciente, feoderma, 17 anos, sexo masculino, foi encaminhando ao serviço de Cirurgia e Traumatologia Bucomaxilofacial, com queixa de aumento de volume na região de maxila e mandíbula à direta, associado a quadros de dores. Durante a anamnese o paciente negou doenças ou comorbidades prévias. Ao exame físico, apresentou assimetria facial, com tumefação em hemiface direita, discreto hipertelorismo, bossa frontal acentuada, múltiplas máculas na região torax e membro superior direito. O exame tomográfico de face evidenciavam-se múltiplas imagens hipodensas em todos os quadrantes da maxila e mandibula. Com base nos critérios diagnósticos o paciente foi diagnostico com a síndrome de Gorlin-Goltz. Após o fechamento do diagnóstico optou-se pela descompressão das lesões maiores e enucleação das menores. Conclusão: O diagnostico clinico para a síndrome de Gorlin-Goltz baseado nos critérios maiores e menores se mostrou eficaz para definição do caso apresentado.

Descritores: Diagnostico; Síndrome do Nevo Basocelular; Patologia.

\section{Abstract}

Introduction: Gorlin-Goltz syndrome is an autosomal dominant hereditary condition, caused by an alteration in the patched gene (PTCH), located on chromosome 9q22.3-q31, this gene regulates the functions of tumor suppression, embryonic organization and cell cycle, mutations in the PTCH gene lead to the effect of losing control of several other genes responsible for organogenesis, carcinogenesis and odontogenesis. Objective: The present study aims to describe a case where the patient was diagnosed with basal cell nevus carcinoma syndrome. Case report: Patient, feoderma, 17 years old, male, who attended the Oral and Maxillofacial Surgery and Traumatology service, complaining of increased volume in the maxilla and mandible region to the right, associated with pain. During the anamnesis, the patient denied previous illnesses or comorbidities. On physical examination, she presented facial asymmetry, with swelling in the right hemiface, slight hypertelorism, marked frontal boss, multiple macules in the thorax and right upper limb. The CT scan of the face showed multiple hypodense images in all quadrants of the maxilla and mandible. Based on the diagnostic criteria, the patient was diagnosed with Gorlin-Goltz syndrome. After the diagnosis was closed, it was decided to decompress the larger lesions and enucleate the smaller ones. Conclusion: The clinical diagnosis for Gorlin-Goltz syndrome based on major and minor criteria proved to be effective in defining the case presented.

Descriptors: Diagnosis; Basal Cell Nevus Syndrome; Pathology.

\section{Resumen}

Introducción: El síndrome de Gorlin-Goltz se entiende como una condición hereditaria autosómica dominante, causada por una alteración en el gen patched $(\mathrm{PTCH})$, ubicado en el cromosoma 9q22.3-q31, este gen regula las funciones de supresión tumoral, organización y ciclo embrionario. las mutaciones en el gen PTCH producen el efecto de perder el control de varios otros genes responsables de la organogénesis, carcinogénesis y odontogénesis. Objetivo: El presente estudio tiene como objetivo describir un caso en el que el paciente fue diagnosticado con síndrome de carcinoma de nevo de células basales. Caso clínico: Paciente, feoderma, 17 años, varón, remitido al servicio de Cirugía y Traumatología Buccomaxilofacial, por aumento de volumen en región maxilar y mandíbula derecha, asociado a dolor. Durante la anamnesis, el paciente negó enfermedades o comorbilidades previas. Al examen físico presentaba asimetría facial, con tumefacción en hemicara derecha, leve hipertelorismo, marcada protuberancia frontal, múltiples máculas en tórax y miembro superior derecho. La tomografía computarizada de la cara mostró múltiples imágenes hipodensas en todos los cuadrantes del maxilar y la mandíbula. Con base en los criterios diagnósticos, el paciente fue diagnosticado de síndrome de Gorlin-Goltz. Una vez cerrado el diagnóstico, se decidió descomprimir las lesiones más grandes y enuclear las más pequeñas. Conclusión: El diagnóstico clínico del síndrome de Gorlin-Goltz basado en criterios mayores y menores demostró ser efectivo para definir el caso presentado.

Descriptores: Diagnóstico; Síndrome del Nevo Basocelular; Patología.

\section{INTRODUÇÃO}

A Síndrome de Gorlin-Goltz foi relata pela primeira vez em 1894 por Jarish e Whinte, mas somente em 1960 foi definida por Robert James Gorlin e William Goltz. Pode ser encontrada também com a denominação de síndrome do carcinoma nevoide basocelular, é compreendida como uma condição hereditária autossômica dominante, causada por uma alteração no gene patched (PTCH), localizado no cromossomo 9q22.3-q31 $1^{1-4}$. Este gene regula as funções de supressão tumoral, organização embrionaria e ciclo celular, as mutações no gene
PTCH levam a o efeito da perda de controle de varios outros genes responsáveis pela organogênese, carcinogêneses e odontogênese ${ }^{1,4}$. Várias características clinicas e radiográficas são encontradas nestes pacientes, múltiplos carcinomas basocelulares, vários queratocistos, depressões palmoplantares, foice do cerebro calcificada, entre outras $^{1-3}$. O presente trabalho tem como objetivo descrever um caso onde o paciente foi diagnosticado com a Síndrome do carcinoma nevoide basocelular. 


\section{CASO CLÍNICO}

Paciente, feoderma, 17 anos de idade, sexo masculino, foi encaminhando ao serviço de Cirurgia e Traumatologia Bucomaxilofacial, com queixa de aumento de volume na região de maxila e mandíbula à direta, associado a quadros de dores na região. Durante a anamnese o paciente negou doenças ou comorbidades prévias. Á exame físico, apresentou assimetria facial, com tumefação em hemiface direita, discreto hipertelorismo, bossa frontal acentuada, múltiplas maculas na região tórax $\mathrm{e}$ membro superior direito. Pela oroscopia observou-se abaulamento das tabuas ósseas na região de fundo de sulco vestibular tanto em maxila à direita, como em região mandibular ipsilateral. Exames laboratoriais de rotina foram solicitados, onde não foram evidenciados valores fora dos padrões de normalidade.

O exame tomográfico de face evidenciava-se múltiplas imagens hipodensas em todos os quadrantes da maxila e mandíbula. Os terceiros molares mandibulares encontravam-se associados as lesões, sendo que o dente 48 estava localizado na região da base mandibular. Durante avaliação da radiografia de crânio observamos calcificação da foice do cérebro e alterações morfológicas da vertebra torácica presente na tomografia de tórax (Figuras 1, 2 e 3).
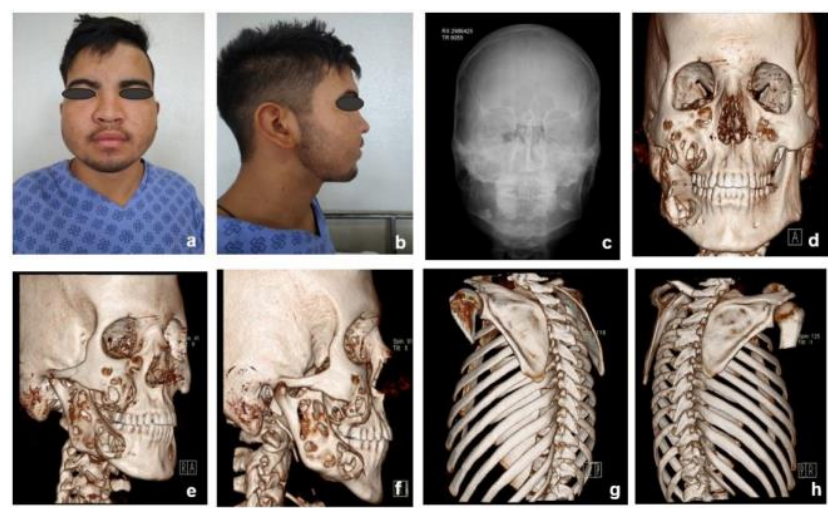

Figura 1: a - fotografia vista frontal; b - vista lateral; c - radiografia evidenciando calcificação da lamina cerebral; d - tomografia de face (reconstrução 3D, evidenciando lesões); e - vista angulada; f - vista lateral; g - tomografia de tórax, vista lateral esquerda (reconstrução 3D, evidenciando alteração em vertebra torácica); $\mathbf{h}$ - vista lateral direita.
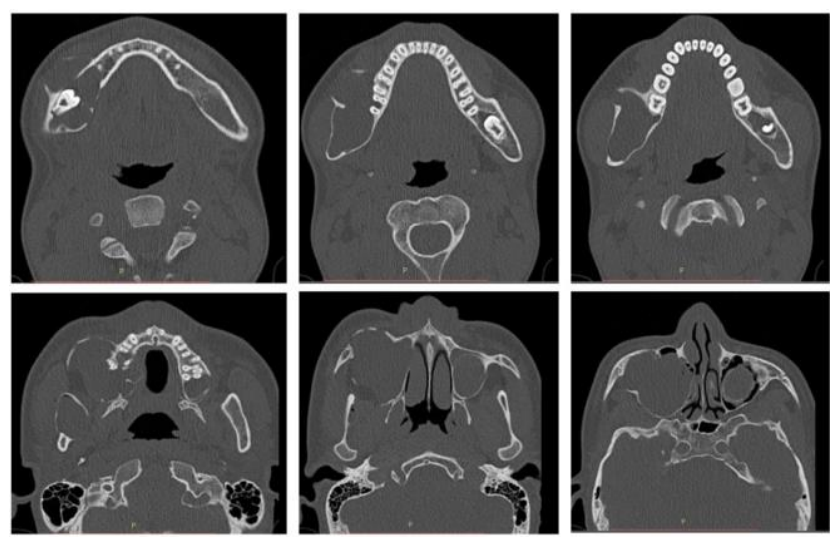

Figura 2: Cortes axiais da tomografia de face evidenciando as lesões císticas envolvendo todos os quadrantes.
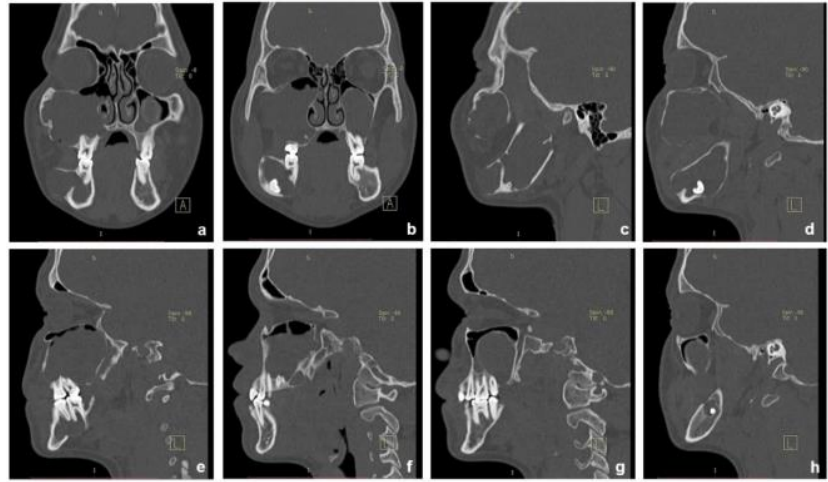

Figura 3: a - corte coronal da tomografia de face; b corte evidenciando 3 molar na base mandibular; $\mathbf{c}, \mathbf{d}, \mathbf{e}, \mathbf{f}, \mathbf{g}$ e $\mathbf{h}$ - cortes sagitais da tomografia de face mostrando o envolvimento das lesões císticas.

Para definição do diagnóstico, foram levados os critérios estabelecidos por Evans et al. ${ }^{5}$, em 1991, modificados por Kimonis ${ }^{6}$ em 1997.Dentre os critério os, observamos que o paciente em questão apresentava macrocefalia $(61 \mathrm{~cm}$ de circunferência), calcificação lamelar da foice cerebral, presença de lesões compatíveis com ceratocistos em todos os hemiarcos, pronunciamento da bossa frontal, lesões em pele compatíveis com carcinomas basocelulares. $\mathrm{O}$ paciente foi então submetido a um procedimento de punção aspirativa das lesões e biopsias incisionais em ambos os seios maxilares, assim como em região de abaulamento ósseo mandibular direito e as máculas de tórax e membro superior. Ambos os procedimentos aconteceram sob anestesia local. Como conclusão obtivemos o resultado de queratocistos e nevos melanocíticos, descartando os carcinomas basocelulares. Após a con firmação pela biopsia, o paciente foi submetido à instalação de drenos para descompressão em maxila e mandíbula à direita, associado à enucleação e curetagem das lesões menores (seio maxilar esquerdo e mandíbula ipsialteral, com envolvimento do terceiro molar). Nos sítios onde foi optado por enucleação e curetagem, foi utilizada solução de Carnoy. Os procedimentos foram realizados em centro cirúrgico, sob anestesia geral, com intubação nasotraqueal. Novamente obtivemos o resultado de ceratocistos, em ambos os seios maxilares e mandíbula, bilateralmente.

DISCUSSÃO

A síndrome do carcinoma nevoide basocelular compreende desordem genética rara, que afeta o gene PTCH, com baixas taxas de incidência 1 em 50.000-150.000, com uma prevalência que pode variar de 1/57.000 a 1/256.000, com a proporção de homens para mulheres de $1: 1$, a síndrome costumase apresentar sinais entre as idades de 17 a 35 anos $^{2,4}$. No atual caso o paciente foi diagnosticado aos 17 anos, indo de encontro com os achado na literatura. 
O padrão atual de diagnóstico da síndrome utilizado neste trabalho foi o de Evans et al. ${ }^{5}$, modificado por Kimonis ${ }^{6}$ em 1997, baseado em critérios maiores e menores, e compreende avaliação das manifestações clinicas e radiográficas. Para o diagnóstico, basta a presença de dois critérios maiores ou um maior e dois menores ${ }^{1,3,4,7}$. Os testes genéticos para identificação na alteração no gene PTCH podem ser realizados para conclusão do diagnóstico ${ }^{1,3}$.

São critérios maiores: 1) mais de 2 carcinomas basocelulares, um carcinoma basocelular em pacientes com menos de 30 anos de idade ou mais de 10 nevos de células basais; 2) qualquer queratocisto odontogênico (comprovado por histologia); 3) três ou mais poços palmares ou plantares; 4) calcificação ectópica em pacientes com 20 anos de idade (calcificação cerebelar lamelar ou falciforme precoce); 5) história familiar positiva de NBCC. Como critérios menores estão elencados: 1) anomalia esquelética congênita (vértebras e costelas, bífida, espalhada, fundida ou ausente); 2) circunferência occipital-frontal aumentada, com protuberância frontal acentuada; 3) fibromas cardíacos ou nos ovários; 4) meduloblastoma; 5) cistos linfomesentéricos; 6) malformações congênitas como fissura labial/palatina, polidactilismo ou anomalia ocular( catarata, coloboma, microftalmia) ${ }^{6}$.

No presente trabalho, o paciente apresentava dois critérios maiores e três menores, sendo assim possível confirmar o diagnóstico de síndrome de Gorlin-Goltz. Apesar de todos os requisitos para diagnóstico clínico serem pré-existentes, o paciente foi encaminhado ao geneticista para confirmação.

$\mathrm{O}$ aparecimento de lesões de carcinoma basocelular é previsto em 50\% a $97 \%$ dos pacientes portadores da síndrome ${ }^{1,7}$. No caso em questão, não foram obtidos resultados confirmativos de carcinoma nas lesões biopsiadas, porém, a faixa etária onde prevalece o seu aparecimento se dá até a terceira década de vida. A presença de queratocistos em portadores da síndrome do carcinoma acomete de $65 \%$ a $100 \%$ dos casos, sendo mais comum seu aparecimento entre a primeira e segunda década de vida, corroborando com o encontrado neste trabalho. Porém, sabe-se que já foram relatados casos onde pacientes não sindrômicos apresentaram 0 acometimento de ceratocistos em mais de uma hemiarcada. Desta maneira, avaliação clínica, imaginológica e genética, se faz imprescindível para definição do diagnóstico ${ }^{1,2,7}$.

O tratamento das lesões císticas pode variar muito, dependendo da extensão da lesão, envolvimento de estruturas nobres, grau de colaboração do paciente ${ }^{1,8,9}$. Podemos lançar mão da enucleação com curetagem associada a osteotomia periférica em lesões menores, ou ainda utilizar métodos coadjuvantes como a solução de Carnoy ou a crioterapia ${ }^{1,8,9}$. Em casos onde observamos grandes lesões, com possibilidade de mutilações demasiadas, optamos por realizar descompressão, uma vez que os ceratocistos respondem bem a esta modalidade de tratamento ${ }^{1,8,9}$.

A descompressão pode trazer uma redução do volume total da lesão de até $75 \%$, em casos de acompanhamento de aproximadamente 2 a 7 anos. Quando lançamos mão desta modalidade de terapia, reduzimos consideravelmente as morbidades $\mathrm{e}$ índices de mutilações do paciente, uma vez que preservamos as estruturas adjacentes ao sítio patológico ${ }^{9}$. O tratamento se baseia em abordagens e acompanhamento multidisciplinar. Como as alterações e lesões da síndrome de Gorlin-Goltz não oferecem risco à vida, o prognóstico vai depender do comportamento dos carcinomas basocelulares e meduloblastoma. Um tratamento e acompanhamento multidisciplinar se faz necessário devido ao envolvimento de múltiplos órgãos ${ }^{10}$. Os múltiplos queratocistos devem ser tratados da mesma forma que os isolados, de tal modo que o acompanhamento clínico e radiográfico deve ser realizado.

\section{CONSIDERAÇÕES FINAIS}

O diagnóstico clinico, baseado nos critérios já estabelecido por Evans et al. ${ }^{5}$ em 1991, se mostrou eficaz para definição do caso apresentado neste trabalho. O estabelecimento da patologia ainda é de difícil execução, uma vez que, em sua maioria, os critérios de Evans apenas são observados quando o paciente apresenta exacerbação de algumas características presente na síndrome. Após o diagnostico o acompanhamento multiprofissional se faz necessário devido envolvimento complexo da síndrome.

\section{REFERENCIAS}

1. Neville BW, Allen CM, Damm DD, Bouquot JE. Patologia: Oral e Maxilofacial. 4.ed. Rio de Janeiro: Guanabara Koogan; 2016. p. 654-63

2. Ribeiro PL, Souza Filho JB, Abreu KD, Brezinscki MS, Pignaton CC. Syndrome in question: Gorlin-Goltz syndrome. An Bras Dermatol. 2016;91(4):541-43.

3. Bresler SC, Padwa BL, Granter SR. Nevoid Basal Cell Carcinoma Syndrome (Gorlin Syndrome). Head Neck Pathol. 2016;10(2):119-24.

4. Ramesh M, Krishnan R, Chalakkal P, Paul G. Gorlin-Goltz Syndrome: Case report and literature review. J Oral Maxillofac Pathol. 2015;19(2):267.

5. Evans DG, Sims DG, Donnai D. Family implications of neonatal Gorlin's syndrome. Arch Dis Child. 1991;66(10 Spec No):1162-63.

6. Kimonis VE, Goldstein AM, Pastakia B, Yang ML, Kase R, DiGiovanna JJ et al. Clinical manifestations in 105 persons with nevoid basal cell carcinoma syndrome. Am J Med Genet 1997; 69:299-308. 
7. Seo DU, Kim SG, Oh JS, You JS. Treatment of nevoid basal cell carcinoma syndrome: a case report. J Korean Assoc Oral Maxillofac Surg. 2016;42(5):284-87.

8. Gupta A, Bansal P, Sharma R, Sharma SD. Treatment of Keratocystic Odontogenic Tumours: A Prospective Study of 30 Cases. J Maxillofac Oral Surg. 2016;15(4):521-27.

9. Park JH, Kwak EJ, You KS, Jung YS, Jung HD. Volume change pattern of decompression of mandibular odontogenic keratocyst. Maxillofac Plast Reconstr Surg. 2019;41(1):2.

10. Vieira EC, Abbade LPF, Marques SA, Marques MEA, Stolf HO. Síndrome de Gorlin. Diagn Tratamento. 2012;17(3):110-14.

\section{CONFLITO DE INTERESSES}

Os autores declaram não haver conflitos de interesse.

\section{AUTOR PARA CORRESPONDÊNCIA}

\section{Maylson Alves Nogueira Barros}

Rua Rui Barbosa, 4744 - Centro

79035-140 Campo Grande - MS, Brasil

E.mail: maylson.bucomaxilofacial@gmail.com

Submetido em 01/07/2019

Aceito em 20/04/2020 